\title{
Migrants' Vulnerabilities and Their Responses to the COVID-19 Pandemic: A Case Study of Mobile Shoe Shine Boys in the Cape Coast Metropolis
}

King David Dzirasah ( $\nabla$ dzirasahkingdavid@gmail.com )

University of Cape Coast

\section{Research Article}

Keywords: Migration, Covid-19 and Shoe-Shine Business in Cape Coast

Posted Date: June 1st, 2021

DOl: https://doi.org/10.21203/rs.3.rs-568008/v1

License: (c) (1) This work is licensed under a Creative Commons Attribution 4.0 International License.

Read Full License 


\section{Abstract}

Covid-19 pandemic has impacted socio-economic activities in sub-Saharan Africa and Ghana for that matter. Occupations in the informal sector such as shoe-shine business have been affected by the disease outbreak. This paper focuses on migrant vulnerabilities and their responses to Covid-19 with a specific focus on shoe-shine boys in Cape Coast Metropolis. The study is guided by the IOM determinants of migrant vulnerability model, empirical review on the shoe-shine business and conceptual framework on shoe-shine business within the informal sector. Using an interview guide, ten shoe-shine boys were interviewed in the Cape Coast Metropolis. Their responses were transcribed and a content analysis was employed to analyze the data. The main challenges caused by Covid-19 were the reduction in income, decrease in customer base and changes in the nature of work. The study concluded that the irregular nature of the shoe-shine business exacerbated the impact of the covid-19 on the occupation but individual coping strategies were key in ensuring the sustainability of the occupation.

\section{Introduction}

At the beginning of December 2019, an outbreak of coronavirus disease 2019 (COVID-19), caused by a new severe acute respiratory syndrome coronavirus (SARS-CoV-2), occurred in Wuhan, Hubei Province, China. On January 30, 2020, the World Health Organization stated that the outbreak was an international public health emergency (Harapan et al. 2020). As of March 18, 2021, there were 121,759,109 laboratoryconfirmed cases and 2,690,731 deaths worldwide (World Health Organization, 2021). Sub-Saharan African countries with Ghana not being an exception have also been impacted by the emergence of Covid-19.

Sub-Saharan Africa accounts for almost 60 percent of the global population living in extreme poverty (World Bank, 2020). Although there has been a significant improvement over the past decade, there is still too little information on the health situation in Africa. The Africa Centres for Disease Control and Prevention (2020) reported that Africa confirmed its first case of COVID-19 in Egypt on February 14. On 27 February, Nigeria reported the first official case of SARS-CoV-2 in the sub-Saharan region, and on 18 March, Burkina Faso's first death occurred. Ghana recorded its first two cases of COVID-19 infection on 12 March 2020 (Afriyie, Asare, Amponsah \& Godman, 2020). The cases increased subsequently with concomitant socio-economic implications for the country. Activities within the informal sector of the economy have also been largely affected by the outbreak of Covid-19.

Young people in Ghana migrate from rural areas and other places with fewer economic opportunities to take up occupations within the informal sector. Some of these migrants end up being shoe-shiners and 'kayayei' (Thorsen, 2009). According to tanle (2018b), no specific definition exists for shoe-shine business. However, the shoe-shine business is mainly performed by young men who often move around or stay in a particular place to polish and/or repair shoes. Those engaged in the shoe-shine business have also been affected by the Covid-19 pandemic. This study aims to study how migrants who engage in shoe-shine business in the Cape Coast metropolis have been affected by the Covid-19 pandemic and 
how they have responded to Covid-19 impact on their work. The research focused on the mobile shoe shiners within the Cape Coast Metropolis.

The research focuses on three objectives. 1. To explore the nature of the shoeshine business before and during Covid-19. 2. To examine challenges associated with the business before and during Covid-19. 3 . To explore coping strategies adopted by the shoe-shine boys before and during Covid-19. The report is split into six parts which are the introduction, conceptual perspective and theoretical framework, survey area, data and methods, results and discussions, conclusions.

\section{Conceptual Perspectives}

Migration is a permanent change of residence or the movement of people in space often involving a change in the usual place of residence. This usually brings about the detachment from the organization of activities at one place (the place of origin) and the movement of the total round of activities to another place (the place of destination) (Goldscheider, 1971). International Organization of Migration (2019), also defines migration as the movement of persons away from their place of usual residence, either across an international border or within a State. This study however will adopt the definition of Goldscheider, 1971 to represent the concept of migration.

International Organization for Migration (2019), defines the concept of migrants as a person who moves away from his or her place of usual residence, whether within a country or across an international border, temporarily or permanently, and for a variety of reasons. The term includes several well-defined legal categories of people, such as migrant workers; persons whose particular types of movements are legallydefined, such as smuggled migrants; as well as those whose status or means of movement are not specifically defined under international law, such as international students.

Migrant worker is a common concept identified in many studies revolving around migration. A migrant worker is defined in the International Labour Organization (ILO) instruments as a person who migrates from one country to another (or who has migrated from one country to another) with a view to being employed other than on his own account and includes any person regularly admitted as a migrant for employment. Migrant workers are particularly vulnerable with respect to limited rights and protection (International Labour Organization (Usher, 2004).

Migrants in vulnerable situations are migrants who are unable effectively to enjoy their human rights, are at increased risk of violations and abuse and who, accordingly, are entitled to call on a duty bearer's heightened duty of care (IOM, 2004). While migration can be a positive experience for many people, it also implies risks and compromises for those who move and those who stay behind. The results of migration depend in large part on who travels, under what conditions and how they fare at their destination.

The concept "the informal sector" was first employed in Africa. It was used by Keith Hart and the ILO to describe the scope of employment and income generating activity outside of formal enterprises that is 
evident in African nations. Hart (1973) used this concept in his study of urban labour markets in Accra, Ghana. He looked at the informal economy in terms of a dualistic model of income opportunities for the urban labour force, based largely on the distinction between salaried employment and self-employment. Informality has been applied to those who are self-employed. Hart emphasized the diversity of activities in the informal economy that went beyond "shoeshine boys and sellers of matches".

The concept of informal employment is intended to encompass employment relationships that are not regulated by formal economic regulations and/or basic legal and social protections. In many cases, the term "informal employment" is used in labour markets in developing countries. Among high-income economies, the term "non-standard" or "a-typical" is more common. Both of those concepts are different. Informal employment generally refers to employment that is not governed by legal or economic regulations. In other words, the focus is on the regulatory status of the enterprise or the job. The term 'non-standard employment' refers to changes in the employment relationship with respect to a dominant or traditional form. In such cases, emphasis is placed on the economic arrangement and the nature of the employment contract (Heintz \& Valodia, 2008).

\section{Theoretical Framework}

The study utilizes and adapts the IOM Determinants of Migrant Model. International Organization for Migration's approach to migrant vulnerability is rooted in the belief that the human rights of all persons, including migrants, should be upheld and promoted and that all vulnerable migrants, regardless of category or status, should be afforded the protection and assistance services that they require. The model includes both vulnerability and resilience. It, therefore, considers both risk factors and protective factors and how the two interact. The model recognizes that migrants and their households/families, communities and groups are all situated in a larger social environment. It considers both resilience and vulnerability to be ascertained by the presence, absence and interaction of risk and protective factors at different levels: individual, household/family, community and structural. Each factor, at each level, is considered either a risk or a protection factor, depending on the context (IOM, 2004).

Individual factors are factors related to individuals: their status in society; their physical and biological characteristics; their histories and experiences; their beliefs and attitudes; their individual emotional, psychological and cognitive characteristics; and their physical and mental health and well-being. Individual characteristics are central to vulnerability and resilience, as they act as a mediator in the way individuals respond to family, community and structural contexts. All people have rights, and the degree to which a person's rights are respected will affect how individual factors affect vulnerability or resilience. Some examples of individual factors are age, sex, racial and/or ethnic identity, sexual orientation, gender identity, personal history, mental and emotional health, and access to resources such as money, goods or support (IOM, 2004).

Household and family factors refers to the family circumstances of individuals and their family members, the role and position of individuals within the family, and the family background and 
experiences. Families are important in determining vulnerabilities, as they are generally the first option for people in need of support, especially children and youth. All household and family members are rights holders, and the degree to which their rights are respected will influence how family and family factors influence vulnerability or resilience. Examples of household and family factors include family size, household structure, socioeconomic status, immigration history, employment, livelihoods, educational attainment, discrimination based on gender and family dynamic (IOM, 2004).

With regard to the community factor, individuals and their families fall into a broader context of the physical and social community. They are impacted by the economic, cultural and social structures of their communities and their position in those structures. Communities with strong social networks and access to resources can provide support and protection to individuals and families, whereas communities without such networks and resources can create risk factors for individuals and families. Some community factors can have different impacts on groups in the community, making some groups more vulnerable and others less vulnerable. For example, social networks which support some groups but exclude others work to protect some and increase the risk for others. Some risk and protective elements can apply to all members in a community, establishing the community as a whole more or less vulnerable. Everyone in a community is a rights holder, and the extent to which their rights are respected will affect how community factors affect vulnerability or resilience. Examples of community factors include availability of quality educational opportunities, health care and social services; equal access to resources; livelihood and income-generating opportunities; the natural environment; and social norms and behaviours (IOM, 2004).

At the broadest level, structural factors are the political, economic, social and environmental conditions and institutions at national, regional and international levels that influence the overall environment in which individuals, families and communities are situated and which shape their beliefs, decisions and behaviours. Structural factors are generally relatively stable, with short- and long-term effects. Examples of structural factors include the history of settlement and conflict, political systems, migration policies and governance, respect for human rights and the rule of law (IOM, 2004).

\section{Empirical Review}

Migration in Ghana has been largely seen as rural-urban migration. The drive to migrate has often been a response to a combination of several elements, including environmental, physical, economic and social factors (Ghana Statistical Service, 2014). A lot of emphases has been placed on economic factors as the main causes of migration. However, the factors that perpetuate the causes of migration are both economic and uneconomic (Kok, O'Donovan, Bouare, \& Van Zyl, 2003). Migration trends in rural Ghana have not changed significantly over the last three years and about $80 \%$ of Ghanaians migrate for some economic reason. Progressively, more are migrating to seek employment or better job opportunities; and for the intent of seeking better business opportunities, males tend to migrate more (Teye, 2019). 
In a study titled: Assessing the Effects of Streetism on the Livelihood of Street Children: A Case Study of Kumasi (in Ghana), Awatey (2014), reveals that children who live on the street engage in various activities which mainly take place in the informal sector such shoe shining. This finding is corroborated by another study conducted by Abebe (2008) which reveals that shoe-shining is one of the economic activities children in poverty situation in Addis Ababa- Ethiopia.

Tanle (2018a), in a study titled "Young Men on the Move to Polish Shoes in the Cape Coast Metropolis, Ghana" reveals that a shoe shiner typically carries a wooden box that contains all the materials necessary for the work. For the most part, they work every day of the week. Much of the day consists of walking and announcing their presence by occasionally hitting the wood box with one of their tools. The shoe shoeshine business is primarily occupied by men. It is mostly carried out by young men under 30 years old. This is because work involves a lot of walking all day long, which might be too tedious for young girls. Tanle (2018a) further found that majority of those who engage in shoe-shine business in the Cape Coast Metropolis migrate from three towns which are Asante Bekwai, New Adubiase and Assin areas. The study also revealed that the main motive for migration was economic. Remittances, investment, employment were identified as primary in the shoe-shine business.

In another study titled Concerns and Intentions among Young Migrants in the Shoe-shine Business in the Cape Coast Metropolis, Ghana, Tanle (2018b) found that obstacles with accommodation and health issues were identified as some of the concerns amongst shoe-shine boys in the Cape Coast Metropolis. It was further revealed that some of the shoe-shine boys experience physical stress as a result of the nature of their work

\section{Study Area}

Cape Coast Metropolis is one of Ghana's six metropolises and the only one out of the 20 districts in the central region. The Assembly is divided into two Sub Metros: the Cape Coast South Sub Metro and the Cape Coast North Sub Metro. It takes in two constituencies which are coextensive with the Sub Metros. Christianity has long been the dominant religion in the Metropolis, although there a significant number of Muslims and traditionalists (Ghana Statistical Service, 2014). The Metropolis, covering an area of approximately 122 square kilometers, has an estimated population of 169,894 , of whom $48.7 \%$ are men and $51.5 \%$ are women (Ghana Statistical Service, 2012).

\section{Data And Method}

Due to the unavailability of information on the number of shoe-shine boys there in the Cape Coast metropolis, the sample size could not be determined. The study however adopted purposive sampling. Ten shoe-shine boys were interviewed for the study. An interview guide was used by the research to facilitate the data collection. The interview was transcribed and the data analyzed employing content analysis based on common themes and direct quotes from respondents. Data was collected from the following areas within the metropolis: Kotokraba, Abura and UCC. 


\section{Results And Discussion \\ Background Characteristics of Respondents}

The background characteristics that this study focused on were age, educational level, occupation, ethnic background, religious affiliation, marital status and place of residence.

Table 1: Socio-demographic characteristics of respondents $(\mathrm{N}=10)$ 


\begin{tabular}{|c|c|c|}
\hline Characteristics & Frequency & Percentage \\
\hline \multicolumn{3}{|l|}{ Age } \\
\hline $20-29$ & 2 & 20 \\
\hline $30-39$ & 6 & 60 \\
\hline $40-49$ & 2 & 20 \\
\hline \multicolumn{3}{|l|}{ Ethnicity } \\
\hline Akan & 7 & 70 \\
\hline Ewe & 1 & 10 \\
\hline Ga/Adangbe & 1 & 10 \\
\hline Mole Dagbani & 1 & 10 \\
\hline \multicolumn{3}{|l|}{ Marital Status } \\
\hline Not Married & 7 & 70 \\
\hline Married & 3 & 30 \\
\hline \multicolumn{3}{|l|}{ Level of Education } \\
\hline Primary & 3 & 30 \\
\hline Middle/JSS & 6 & 60 \\
\hline Secondary & 1 & 10 \\
\hline \multicolumn{3}{|l|}{ Occupation } \\
\hline Shoe-shine Business & 10 & 100 \\
\hline \multicolumn{3}{|l|}{ Residence } \\
\hline Kotokraba & 2 & 20 \\
\hline Abura & 3 & 30 \\
\hline Amamoma & 1 & 10 \\
\hline Apewosika & 1 & 10 \\
\hline Antem & 3 & 30 \\
\hline \multicolumn{3}{|l|}{ Religion } \\
\hline Christianity & 7 & 70 \\
\hline Islam & 2 & 20 \\
\hline African Traditional Religion & 1 & 10 \\
\hline
\end{tabular}




\begin{tabular}{|lll|}
\hline Duration at place of residence (years) & & \\
\hline$>1$ & 2 & 20 \\
\hline$<-10$ & 6 & 60 \\
\hline 11 & 2 & 20 \\
\hline Number of Occupants at Place of Residence & & \\
\hline $1-5$ & 8 & 80 \\
$6-10$ & 2 & 20 \\
\hline
\end{tabular}

Source: Fieldwork, March 2021

\section{Place of Origin}

Respondents indicated that they migrated from the following towns: Abokrom-Kissi, Mankessim, Accra, Asante Bekwai, Kaneshie, Adansi Fomena and Elmina.

\section{Purpose for Migrating}

While some of the respondents mentioned that they wanted to change their working environment, employment opportunity was the major factor they migrating. The study revealed that economic factors serve as a key reason for individuals who migrated to Cape Coast Metropolis to engage in shoeshine business. According to Ghana Statistical Service (2014), economic factors are the main drivers for migration. Most of the research participants mentioned work or employment as the main reason they migrated to Cape Coast:

I moved to Cape Coast to work and landed in this shoe shine business because man must survive. I am guy and everyone looks up to me (28, married, Secondary School).

\section{Nature of Work}

Some of the respondents mention that they needed to get a job and the shoe-shine business was the employment opportunity available at the time. They believed the shoe-shine business offered them the opportunity that they need to work and they could not sit idle without doing anything:

It's a long story but in all, after school, my dad died and I couldn't get support from anywhere. I sat in the house and I said man has to work to make ends needs. Then, I decided to get some job doing. That is how I came into this shoe shine business (28, married, Secondary School).

Respondents indicated that they got start-up capital for the shoe-shine business from their friends and family. This is consistent with the theoretical proposition of the determinants of migrant vulnerability model which postulates that families are important in determining vulnerabilities, as they are generally 
the first option for people in need of support, especially children and youth (IOM, 2004). The following quote is a response from one of the participant:

I took money from my mother to buy plenty things [working gears] to start everything. I took like 7 cedis from her to buy stuffs for the shoe shine job (42, not married, Primary School).

The participants indicated that before the Covid-19 pandemic, their operations in the shoe-shine business was good. They were able to make a lot of money and take care of their families at home. Work was normal before the covid-19 as captured in the following excerpts:

Work was good and fruitful. I enjoyed working because I could make lots of money and able to help others and family members. Before covid, working was smooth and enjoyable (28, not married, Secondary School).

Participants mentioned that the covid-19 has affected the work. Their work is no longer the way it was on a normal day. The income they get has reduced and their customer base has also been affected by covid19. This finding is consistent with findings made by Tanle (2018b) who reveal that health issues were an obstacle in the shoe-shine business in the Cape Coast Metropolis. The following is a quote from a respondent:

Covid has affected me paaaa. I don't get to money as I use to get so; I owe my landlady rent for 2 months (42, not married, primary school).

Respondents indicated that they made several rounds a day before the covid-19 came. Rounds mentioned range from six to ten. Some make as many as six rounds while others make as many as ten rounds on a normal day:

Oh, like 10rounds because I move from one community to another (25, not married, Junior Secondary School).

From the data, respondents indicate that their rounds on a normal day has reduce as a result of Covid- 19 . The following is an excerpt from one of the respondents:

It has reduced and since you are a student you know what it entails. But my special customers call me when there is work to be done $(35$, married, primary school).

With income, the respondents mention that they make between 400 Ghana cedis to 1000 Ghana every month before they were hit by the Covid-19 pandemic:

I can get like 700-750cedis or even more depending on the number of work or rounds I go on daily basis (28, married, Secondary School).

From the data, respondents indicated that their monthly has been affected by the pandemic. They make between 350 cedis to 750 cedis a month. 


\section{Challenges and coping strategies in the Shoe-shine business}

Respondents mention getting tired as challenges they faced before the covid-19 him them. This is due to how physically demanding the work is as they have to walk long distances. This finding is consistent with finding made by Tanle (2018b) who revealed that shoe-shine boys within the cape coast metropolis experience physical stress as a result of the nature of their work. The following is a quote from one of the respondents:

The challenge I can talk of is just that I come home very tired and even sometimes it's very difficult to sit with my family (35, married, primary school)

Ability to work, customer base and income have been mention as being areas of their work that has been affected by Covid-19. The following is a quote from a respondent:

It is very bad to the extent that some days I don't go to work (25, not married, Junior High School).

Respondents indicated that they rest, work late in the day or depend on family support to overcome the challenge of physical tiredness they faced before the covid-19 pandemic came. Family support they receive is explained by the determinant of migrant vulnerability which postulates that families are important in determining vulnerabilities, as they are generally the first option for people in need of support, especially children and youth (IOM, 2004). The following is an excerpt by one of the respondents:

Though, it was difficult dealing with it but I spoke to them [family] and explain certain things to them until I was able settle them (28, cohabitating, Secondary School).

From the data, respondents have mentioned that they are managing the situation created by the covid-19 with respect to their work:

We are managing with the small income we get at the end of every work and God is protecting and blessing us (35, not married, Junior School).

\section{Benefit from shoe-shine business}

Having a job, being able to take care of family and earning income were the benefits from the shoeshine business. The respondents revealed that through the shoe-shine work they can be able to get money to support their family. This finding is consistent with findings made by Teye (2019) who reveals that people migrate to get better jobs and employment opportunities. The following is a quote from one of the respondents:

There are so many benefits from this job. I can pay my kids fees; I have a store for my wife and at the same time she is a seamstress and I am very happy $(35$, married, Primary School).

\section{Conclusion}


Economic factor such as the unavailability of jobs is one of the main drivers of migration. Shoe-shine business in Cape Coast Metropolis provides employment opportunities for many youths in places where unemployment seems to be prevalent. Many of these individuals who have either basic education or secondary education depend on the shoe-shine business as means of livelihood and poverty reduction strategy. In addition, the shoe-shine business as an informal sector income opportunity is not without its challenges.

Covid-19 has exposed those within the shoe-shine business to challenges that affect the very nature of the work. There is an evidential basis to conclude that covid-19 has had a rippling effect on the income, nature and even the sustainability of the shoe-shine business in Cape Coast. Lack of regularity of shoe-shine business which falls within the domain of informal sector has exacerbated those within the sector. However, individual coping strategies are critical to the sustainability of the shoe-shine business in Cape Coast Metropolis.

\section{Declarations}

Competing interests: The author declares that they have no competing interests.

\section{References}

Abebe, T. (2008). Ethiopian Childhoods: A Case Study of the Lives of Orphans and Working Children, unpublished Ph.D. Thesis, Department of Geography, NTNU.

Africa Centres for Disease Control and Prevention (2020) Africa CDC-COVID-19 daily updates. https://africacdc.org/covid-19/

Afriyie, D. K., Asare, G. A., Amponsah, S. K., Godman, B. (2020). COVID-19 pandemic in resource-poor countries: challenges, experiences and opportunities in Ghana. J Infect Dev Ctries; 14(8):838-843. doi:10.3855/jidc. 12909

Ghana Statistical Service (2012). 2010 Population and Housing Census Report, Ghana

Statistical Service, Accra, Ghana Statistical Service, Noguchi Memorial Institute for Medical Research (NMIMR), and ORC Macro (2009). Ghana Demographic and Health Survey 2008. Calverton Maryland: GSS, NMIMR, and ORC Macro.

Ghana Statistical Service. (2014). Population data analysis reports. Socioeconomic and demographic trends analysis. Ghana Statistical Service, Accra.

Ghana Statistical Service (2014). 2010 Population and Housing Census. District Analytic Report: Cape Coast Municipality. 
Goldscheider, C. (1984). Rural migration in developing nations: comparative studies of Korea, Sri-Lanka and Mali. Boulder and London, Westview Press.

Hart, Keith. 1973. "Informal income opportunities and urban employment in Ghana." Journal of Modern African Studies. 11 (1): 61-89.

Harapan et al., (2020). Coronavirus disease 2019 (COVID-19): A literature review. Journal of Infection and Public Health, 13, $667-673$.

Heintz, J. \& Valodia, I. (2008). Informality in Africa: A Review

International Organization for Migration (2004). The Determinants Of Migrant Vulnerability

International Organization for Migration (2019). Glossary on Migration.

Kok, P., M. O'Donovan, Bouare, O. \& Van Zyl, J. (2003). Post-apartheid patterns of internal migration in South Africa. Cape Town: HSRC.

Tanle (2018a). Young Men on the Move to Polish Shoes in the Cape Coast Metropolis, Ghana.

Tanle A. (2018b). Concerns and Intentions among Young Migrants in the Shoe-shine Business in the Cape Coast Metropolis, Ghana. DOI//http://dx.doi.org/10.4314/gjds.v15i1.3

Teye, J. K. (2019). Changing patterns of migration and remittances: A case study of rural Ghana focused on the three Northern regions; Brong Ahafo and Volta regions; Accra and Tema, Centre for Migration Studies, University of Ghana, Legon, dissemination workshop organized by the Migrating out of Poverty Research Programme Consortium (MOOP-RPC).

The World Bank (2020c) The World Bank data: Sub-Saharan Africa. https://data.worldbank.org/region/sub-saharan-africa.

Thorsen, D. (2009). Mobile Youth With Little Formal Education: Work Opportunities And Practices.

Usher, E. (2004). Migration and labour. Essentials of migration management: a guide for policy makers and practitioners. Geneva: United Nations Publications.

World Health Organization (2021). WHO Coronavirus (COVID-19) Dashboard. Retrieved from https://covid19. who.int/?adgroupsurvey=\{adgroupsurvey $\} \&$ gclid=CjOKCQjwutaCBhDfARIsAJHWnHu7QPpVdly9UGejkyghOs_II-nmoz043DCu4ksfi3mmwSRxGbpdjMaAtKQEALw_wcB

\section{Figures}




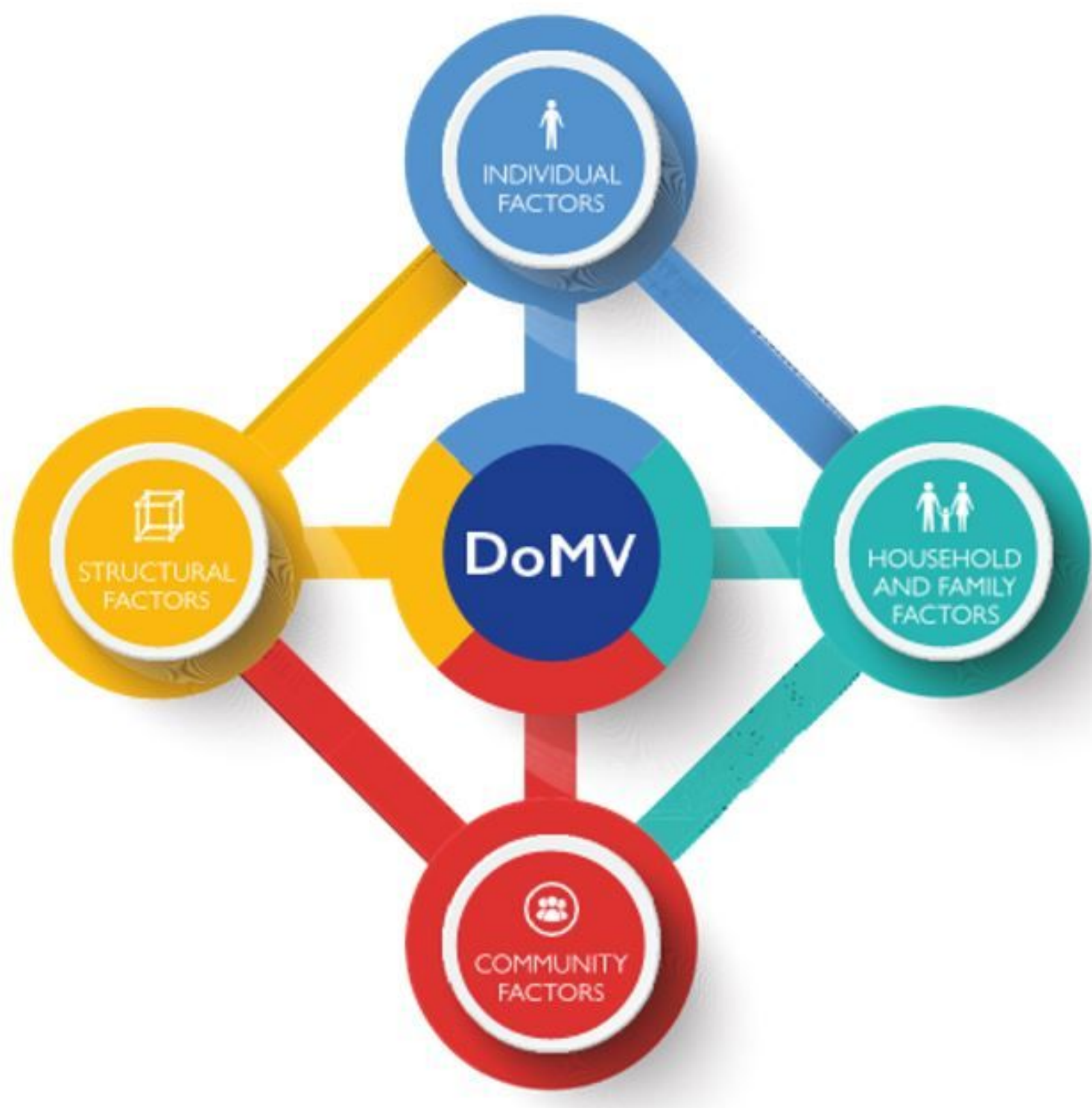

Figure 1

The determinants of migrant vulnerability (DoMV) model Source: International Organization for migration. 


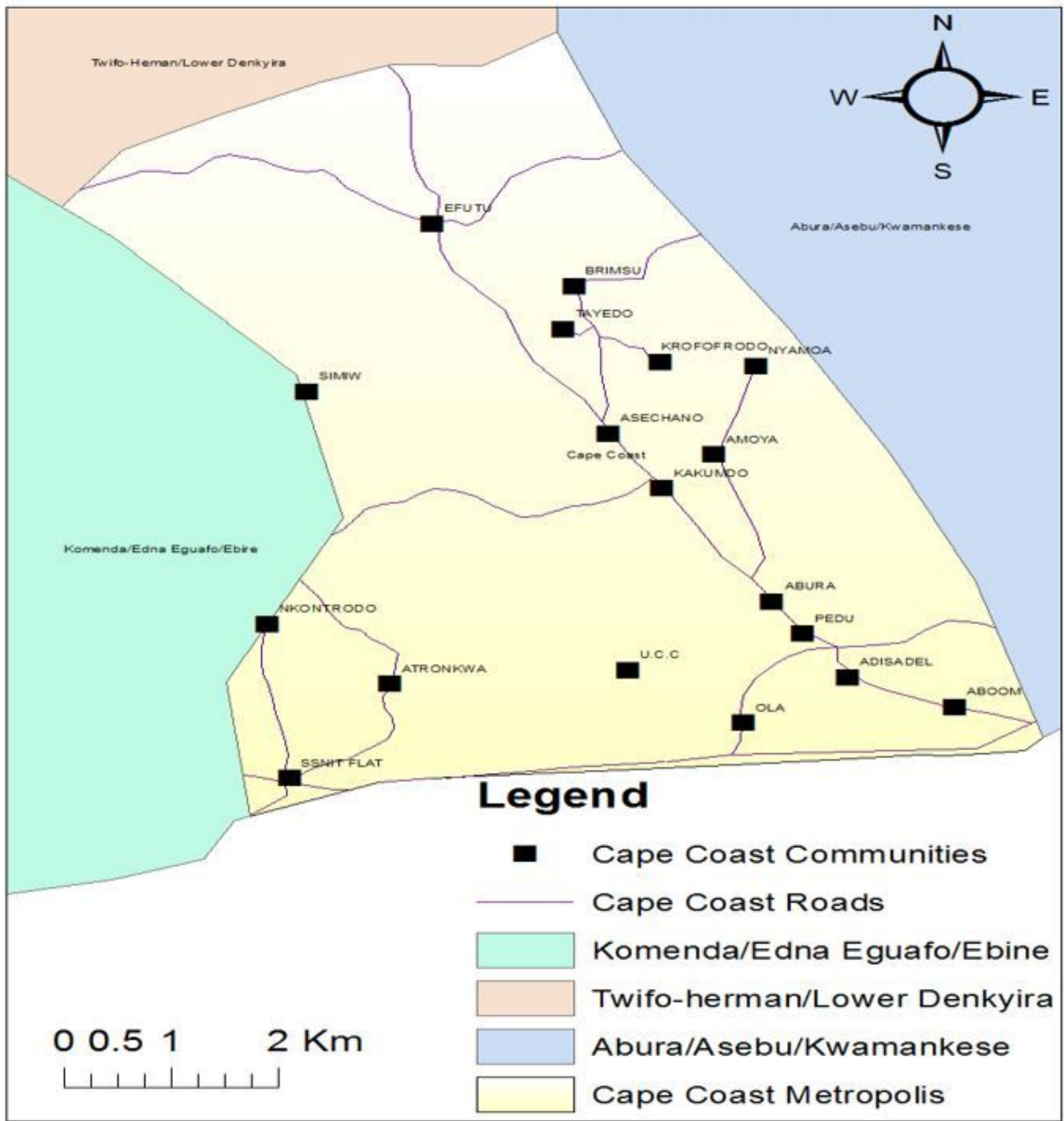

Figure 2

Map showing Cape Coast Metropolis Source: Albert Kwarteng 